DOI (10.1108/HRMID-08-2018-0159);

Human Resource Management International Digest

'Do I fit in?'

Signals on corporate websites

\author{
Emma Stockdale \\ Communication and Change Management \\ Willis Towers Watson \\ UK \\ Dr. Laura William \\ Faculty of Business \\ University of Greenwich \\ UK
}

Tel: 02083319039

Email:1.c.william@greenwich.ac.uk

(Corresponding author)

Dr. Lilith Arevshatian

WWK, Department of Management

Kingston Business School

UK 
DOI (10.1108/HRMID-08-2018-0159);

Human Resource Management International Digest

'Do I fit in?'

Signals on corporate websites

\begin{abstract}
Purpose: Prospective job applicants tend to use signals that are presented on corporate websites to form perceptions about the organisation. Specifically, they decide whether they would 'fit in'. Our research examines the explicit and implicit signals presented by FTSE250 companies on their corporate websites.
\end{abstract}

Design: A content analysis was carried out on FTSE250 corporate websites.

Findings: While many corporate websites do include general references to diversity, they do not engage with different protected characteristics on an equal basis. Furthermore, corporate websites often espouse the legal and business case rationale for engaging with diversity.

Research limitations: We were restricted by the information presented on corporate websites. Further research could employ a multi-modal approach and include analysis of images as well. Practical implications: Companies need to consider their overall rationale for engaging with diversity. Fostering a culture of inclusion where diversity is celebrated will allow companies to showcase their genuine commitment to diversity on their websites and avoid sending disingenuous signals to minority groups.

Social implications: Increasing the perceived 'fit' of minority groups in organisational culture will foster inclusion and diversity and support minority group engagement.

Originality/value: This research examines diversity signals and relates these to job applicants' perceptions.

Keywords: corporate websites, business case, diversity, equality, inclusion, protected characteristics.

\title{
To apply or not to apply?
}

Websites communicate a wealth of information about a company and also send signals to potential job applicants about what it would be like to work there - they are the virtual 'face' of organisations. Website signals can be explicit, such as diversity awards and mentions of specific identity groups (e.g., LBGT or disabled people), or implicit, such as images of diverse groups. Prospective applicants use the explicit and implicit signals presented on corporate websites to form perceptions about whether they would 'fit in' in the organisation. In particular, 
DOI (10.1108/HRMID-08-2018-0159);

Human Resource Management International Digest

minority group applicants are especially cognisant of signals that their group is accepted and supported in the organisation in their decision to apply for a job. Most companies are now aware that a diverse workforce makes business sense and have a vested financial and legal interest in attracting top diverse talent. Companies that employ a diverse workforce often achieve benefits such as increased innovation, reduced employee turnover, and higher profitability. For example, a $10 \%$ increase in gender diversity is estimated to bring a $2-3 \%$ increase in profitability (e.g., Isidro \& Sobral, 2015; Jayne \& Dipboye, 2004). Diversity is also legally mandated in most developed economies. Specifically in Great Britain (GB), the Equality Act 2010 protects nine minority groups against direct and indirect discrimination, harassment, and victimisation (sex, age, race, disability, religion and belief, pregnancy and maternity, marriage and civil partnership, sexual orientation, gender reassignment). Our study showed that although many organisations refer to diversity more generally on their websites, they are often selective in the characteristics that they mention; some of these mentions may even be perceived as disingenuous. We argue that authentic engagement depends on companies' values being genuinely rooted in equality, diversity, and inclusion (EDI).

\section{Research design}

Our study examined the EDI signals presented on FTSE250 corporate websites. We performed a content analysis using an approach similar to Beauregard et al. (2016) by coding the nine protected characteristics as per the UK Equality Act 2010, and analysed information referring to EDI more generally to interpret companies' engagement. We calculated a good inter-rater reliability between two coders with a $96 \%$ agreement.

\section{Key findings}

What signals do applicants pick up when viewing corporate websites?

FTSE250 companies frequently referred to minority groups using collective terms such as 'diversity' (63\%), 'inclusion' (22\%), and 'equality' (19\%). Despite their use, these terms were rarely defined - what exactly did companies mean by 'we value diversity'? They could be referring to some, but not all, of the nine protected characteristics. 
DOI (10.1108/HRMID-08-2018-0159);

Human Resource Management International Digest

The table above shows the number of organisations mentioning each protected characteristic and the website location of each mention. The most commonly mentioned protected characteristics were sex $(55 \%)$ and age (41\%). This is not altogether surprising given that these two characteristics represent a large proportion of society as compared to many of the other characteristics and organisations, therefore, feel a greater pressure to represent these groups. It does not necessarily mean that organisations value these characteristics. Conversely, pregnancy and maternity were the least represented of the protected characteristics (13\%). An insidious finding, perhaps, because persons who take parental leave, especially maternity leave, come at a cost to organisations in terms of entitlements and benefits. Gender reassignment was the second least represented of the protected characteristics (13\%), reflective of the wider silencing of transgender voices in the workplace. Gender identity is also often grouped with sexual orientation under the acronym of LGBT (lesbian, gay, bisexual and transgender) and organisations do not often refer to it separately.

\section{---INSERT TABLE 2 ABOUT HERE---}

The table above examines the frequency of websites showcasing diversity awards. In total only $12 \%$ of organisations displayed an award for diversity on their website. Awards for gender were the most commonly presented followed by awards for gender reassignment and sexual orientation (e.g., Stonewall Diversity Champion).

\section{How is EDI presented?}

The data showed that of the FTSE250 companies which referred to EDI, legal compliance was the most frequently used EDI tool (80\%) followed by valuing diversity (44\%) and the business case $(38 \%)$. The table below shows how EDI is presented in corporate websites.

\section{---INSERT TABLE 3 ABOUT HERE---}

Companies that take a legal compliance route more frequently emphasised organisational policies and the role that these play in supporting minority groups in the workplace (e.g., maternity leave provision) while companies that opted for the business case route tended to present EDI in a way that emphasises its competitive advantage (e.g., increasing competitiveness through diversity). This point raises the question, how exactly do organisations define what is a 'valuable' identity? Organisations may choose to highlight 
DOI (10.1108/HRMID-08-2018-0159);

Human Resource Management International Digest

characteristics that are the most beneficial to them in terms of public perceptions (e.g., women on boards) while omitting characteristics that may be perceived as less profitable (e.g., gender reassignment). For example, where the business case approach is used, women on boards is the most frequently example on websites, but given the 2018 gender pay gap reporting mandate, it is also the most 'beneficial' to companies' image.

When prospective applicants are judging corporate websites for goodness-of-fit, the context in which signals are presented plays an important role in assessing the signal's authenticity (e.g. Brady, Kaiser, Major, \& Kirby, 2015). Organisations that adhere to minimal compliance with the 'letter of the law' instead of a genuine engagement with the 'spirit of the law' are at risk of appearing disingenuous. Indeed, EDI ought to be about celebrating diversity and believing in it in-and-for-itself - it is the 'right' thing to do irrespective of business case arguments or legal mandates.

\section{Recommendations}

- Start from within. EDI should be core to a company's values and culture. Organisations should have a genuine engagement and authentic commitment to celebrating EDI within the workplace. Reflecting this culture on corporate websites should follow naturally and organically.

- Lead by example. Despite advancements in EDI, many organisations are still lagging behind with few minority groups being fairly represented within the workplace. Policies are useful but authentic implementation is paramount. If organisational practices are indeed reflective of EDI values, then finding genuine examples for corporates websites should be easy.

- If you've got it, flaunt it. If you have EDI networks, awards, or statistics that demonstrate commitment to EDI values, then make sure these are presented throughout your website and are easily visible for all to see.

- Check your message. EDI statements should be about celebrating diversity and valuing the difference that all people bring. Highlight successes!

- It's in the detail. Include personal bios from diverse members of staff and showcase the positive workplace experiences of minority groups to demonstrate your company's authentic commitment to EDI. 
DOI (10.1108/HRMID-08-2018-0159);

Human Resource Management International Digest

- Signalling through omission. Remember that communication is not only about what you say, but also about what you don't say. Engage with all nine protected characteristics and do so genuinely.

- Network for success. Consider working with organisations that champion diversity, such as Stonewall or Working Families, and display these alliances on your website.

- Consistency is key. Ensure the messages on your websites are consistent. If you want to celebrate EDI, ensure that your values permeate all through the website and your company culture.

\section{References}

Beauregard, T. A., Arevshatian, L., Booth, J. E., \& Whittle, S. (2016). Listen carefully: Transgender voices in the workplace. The International Journal of Human Resource Management. Advance online publication. doi: 10.1080/09585192.2016.1234503

Brady, L. M., Kaiser, C. R., Major, B., \& Kirby, T. A. (2015). It's fair for us: Diversity structured cause women to legitimize discrimination. Journal of Experimental Social Psychology, 57, 100-110. doi: https://doi.org/10.1016/j.jesp.2014.11.010

Isidro, H., \& Sobral, M. (2015). The effects of women on corporate boards on firm value, financial performance, and ethical and social compliance. Journal of Business Ethics, 132(1), 1-19. doi: 10.1007/s10551-014-2302-9

Jayne, M. E. A., \& Dipboye, R. L. (2004). Leveraging diversity to improve business performance: Research findings and recommendations for organizations. Human Resource Management, 43(4), 409-424. doi: 10.1002/hrm.20033 
Table 1: The number of organisations mentioning specific protected characteristics $(\mathbf{N}=191)$

\begin{tabular}{c|cccccccccc} 
& $\begin{array}{c}\text { Mentioned } \\
\text { at least } \\
\text { once across } \\
\text { the website }\end{array}$ & Age & Race & Sex & Disability & $\begin{array}{c}\text { Sexual } \\
\text { orientation }\end{array}$ & $\begin{array}{c}\text { Gender } \\
\text { Reassig } \\
\text { nment }\end{array}$ & $\begin{array}{c}\text { Pregnancy } \\
\text { and } \\
\text { Maternity }\end{array}$ & $\begin{array}{c}\text { Religion and } \\
\text { Belief }\end{array}$ & $\begin{array}{c}\text { Marriage } \\
\text { and Civil } \\
\text { Partnership }\end{array}$ \\
\hline $\begin{array}{c}\text { Mentioned at } \\
\text { least once }\end{array}$ & 117 & 79 & 75 & 106 & 73 & 64 & 25 & 24 & 53 & 38 \\
$\begin{array}{c}\text { Homepage } \\
\text { Information }\end{array}$ & 7 & 3 & 1 & 3 & 0 & 0 & 0 & 0 & 0 & 0 \\
$\begin{array}{c}\text { pages } \\
\text { Careers }\end{array}$ & 83 & 47 & 48 & 78 & 43 & 37 & 13 & 12 & 29 & 17 \\
$\begin{array}{c}\text { Search } \\
\text { function }\end{array}$ & 38 & 25 & 23 & 22 & 23 & 19 & 6 & 6 & 17 & 9 \\
\end{tabular}


Table 2: The presentation of diversity characteristics by organisations which presented awards

\begin{tabular}{l|ccccccccc} 
& Age & Race & Sex & Disability & $\begin{array}{c}\text { Sexual } \\
\text { orientation }\end{array}$ & $\begin{array}{c}\text { Gender } \\
\text { Reassignment }\end{array}$ & $\begin{array}{l}\text { Pregnancy/ } \\
\text { Maternity }\end{array}$ & $\begin{array}{l}\text { Religion } \\
\text { and Belief }\end{array}$ & $\begin{array}{c}\text { Maternity and Civil } \\
\text { Partnership }\end{array}$ \\
\hline $\begin{array}{l}\text { Number } \\
\text { of } \\
\text { awards }\end{array}$ & 11 & 9 & 20 & 10 & 13 & 13 & 7 & 7 & 7
\end{tabular}


Table 3: Organisations using legal, valuing and business case tools to promote EDI

\begin{tabular}{|c|c|c|c|}
\hline EDI term & Legal $(\mathrm{N}=94)$ & Valuing $(\mathrm{N}=52)$ & Business case $(N=43)$ \\
\hline Diversity & 57 & 36 & 28 \\
\hline Equality & 18 & 11 & 8 \\
\hline Equal opportunities & 34 & 15 & 11 \\
\hline Inclusion & 21 & 11 & 12 \\
\hline Protected characteristics & 4 & 0 & 0 \\
\hline Other terms & 3 & 2 & 1 \\
\hline
\end{tabular}

